\title{
Assessment of Extent and Severity of Pellet Induced Abdominal Injuries, a Rare Variant of Weapon Violence: A Prospective Study
}

\author{
Azher Mushtaq*, Atif Naeem Raja, Hilal Ahmad Wani, Shaukat A. Jeelani, Nazia Hilal, \\ Ishfaq Ahmed Gilkar
}

Government Medical College, Srinagar, India

Email: *azharmushtaq82@gmail.com

How to cite this paper: Mushtaq, A., Raja, A.N., Wani, H.A., Jeelani, S.A., Hilal, N. and Gilkar, I.A. (2016) Assessment of Extent and Severity of Pellet Induced Abdominal Injuries, a Rare Variant of Weapon Violence: A Prospective Study. Surgical Science, 7, 475-483.

http://dx.doi.org/10.4236/ss.2016.710064

Received: September 26, 2016

Accepted: October 16, 2016

Published: October 19, 2016

Copyright $\odot 2016$ by authors and Scientific Research Publishing Inc. This work is licensed under the Creative Commons Attribution International License (CC BY 4.0).

http://creativecommons.org/licenses/by/4.0/

\section{Abstract}

Background: The use of a Pellet gun, a form of short gun used for mob control in many conflict zones, has posed a serious challenge to the surgeons in assessing the extent of trauma caused by these pellets. Objectives: To study the role of conventional available investigations for trauma like ultrasonography and computed tomography scans in assessing the severity of the injuries caused by the pellets. Methodology: 50 patients having pellet injuries predominantly in abdomen without other associated trauma were included in the study. The decision for surgery was taken on the basis of clinical and CECT (Contrast Enhanced Computed Tomography) findings and these findings were then compared with intra-operative findings. Results: 30/50 patients were decided to be operated on the basis of Clinical and CECT findings. On exploration, it was observed that $18 / 33$ patients really needed exploration while as $15 / 33$ patients could have been managed conservatively. This was observed in next 20/50 patients who were put on conservative management with similar CECT findings. Of these 20 patients, 17 did well while as 3 were explored later in view of developing peritonitis and were found to have small bowel perforations. Conclusion: Conventional investigations for trauma like FAST and CECT abdomen are not ideal for assessing the severity of pellet induced abdominal visceral injuries which result in high rate of unnecessary laparotomies. Also the abdominal pellet trauma patients can be well managed conservatively until hemodynamically stable even though CT scan shows pellet penetration into peritoneal cavity or bowel lumen.

\section{Keywords}

Pellets, Bowel Perforation, Laparotomy 


\section{Introduction}

Kashmir, the place known for its breath taking natural beauty that has been referred by the great writers and poets of the world as the "Paradise on the Earth" and "The valley of the Saints", is also unfortunately the region that has witnessed the worst forms of political violence that has killed thousands of civilians and left many more injured and disabled [1]. During the episodes of unrest, the government authorities use different kinds of forces and weaponry to quell the protesters like rubber bullets, conventional bullets, tear gas shells and recently the pellets, a form of short-gun.

Introduced in 2010 by the state police as "Non-lethal weapon" to quell protestors in Kashmir, the pellet gun injuries have posed a serious challenge to the Surgeons in assessing the nature, extent and severity of the trauma caused by these pellets. Because of the paucity of literature available on this rare form of violence and the controversy that exists over whether such patients should have selective or mandatory exploration done; while some favour early abdominal exploration in all abdominal short-gun injuries where intra-abdominal penetration cannot be ruled out (Sherman and parish), others suggest that normotensive abdominal shot gun wounds with a scatter pattern of pellets penetrating the peritoneum can be successfully observed expectantly, even in the advent of ongoing peritonitis [2]. We performed a study to assess the extent, severity and lethality of the injuries caused by these pellets that may help in formulating a protocol for the management of pellet injured patients.

\section{Material and Methods}

The study was performed in a conflict zone during the period of major civil unrest in July 2016. A total of 356 injured patients were received in the emergency department. 45 patients $(12.64 \%)$ had bullet injuries, 7 patients $(1.9 \%)$ were hit by tear gas shells and 304 patients (85.3\%) were the victims of pellet injuries. Among the pellet injuries, 198 patients $(65.13 \%)$ had predominant eye injuries, 30 patients $(9.8 \%)$ had pellets in head and neck region and $58(19.07 \%)$ had pellet injuries in torso.

After arrival in the emergency room, $\mathrm{ABCDE}$ approach of trauma was followed in all patients to ensure their safety. After a thorough preliminary examination, all patients having pellet injuries on torso who formed the material of our study had a Focussed Assessment Sonography for Trauma (FAST Scan) done in the Emergency room by the radiologist and after resuscitation were sent for a CECT Chest, Abdomen and Pelvis and also the required radiographs of the extremities, cervical spine and pelvis were ordered. The patients were operated on the basis of Clinical assessment and CECT findings. The clinical and CECT findings were then compared with intraoperative findings. Patients who were kept on conservative management on the basis of Clinical and CECT findings, their clinical course was closely monitored and the need for later laparotomy noted.

\subsection{Inclusion Criteria}

All patients having exclusive pellet injuries on torso without other associated trauma 
like physical assault or bullet injury were included in the study.

\subsection{Exclusion Criteria}

Patients with Bullet injuries or Physical assault.

Patients with penetrating injuries to abdomen other than pellets.

Patients with pellet injuries to torso associated with other severe organ system injuries like predominant chest trauma or head injury were excluded from the study.

\section{Results}

A total of 356 injured patients were received in the emergency department during this episode of violence. Out of these 356 patients, 45 (12.64\%) patients were having bullet injuries, 7 (1.9\%) were hit by tear gas shells and 304 patients (85.4\%) were hit by pellets in different regions of the body (Table 1).

The predominant site of injury was face and eyes affecting $65.13 \%$ of patients.50 patients (16.45\%) had predominant abdominal pellets and were included in our study.

Overall in a total of 50 patients, 30 patients were operated and 20 were kept on conservative management in our study (Figure 1).

30 patients were operated within 12 hours and 20 patients were kept on conservative management after initial assessment. 3 of the 20 patients under observation developed signs of peritonitis were operated later.

\section{Management Strategy Of Patients}

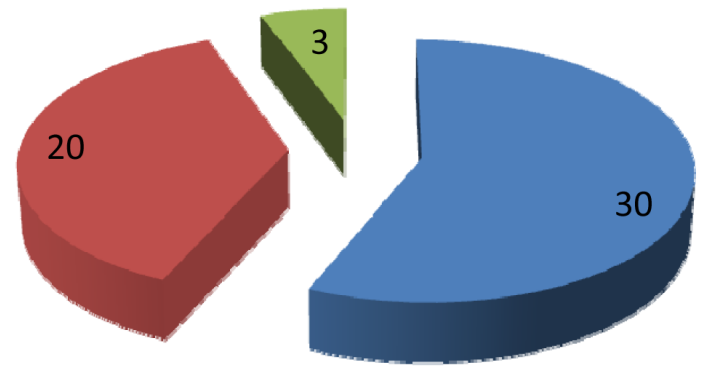

operated within 12 hours

kept on Conservative management

Operated after 48 hours

Figure 1. Management strategy of patients.

Table 1. Anatomic distribution of pellet injuries in our patients.

\begin{tabular}{ccc}
\hline Predominant anatomic site of injury & No. of patients & Percentage \\
\hline Eyes and face & 198 & $65.13 \%$ \\
Head and neck & 30 & $9.8 \%$ \\
Extremities & 18 & $5.9 \%$ \\
Torso & 58 & $19.07 \%$ \\
Abdomen & 50 & $16.4 \%$ \\
Chest & 8 & $2.6 \%$ \\
\hline
\end{tabular}


Clinical findings of injured patients in our study are shown in the figure below (Figure 2).

All patients in our study had multiple pellet wounds on their abdomen and all were complaining of abdominal pain and had diffuse abdominal tenderness.

CECT findings of these patients with predominant abdominal pellets in our study were as Table 2.

The predominant CECT finding in our study was the presence of multiple pellets in the parietal wall (100\% patients), followed by intra-peritoneal pellets ( $92 \%$ patients) followed by the pellets inside hollow viscera (74\% patients). The pellet on CT scan produced a "Sun Ray appearance" or the appearance was similar to that of the "Spokes of a wheel", Figure 3(a).

- Tachycardia
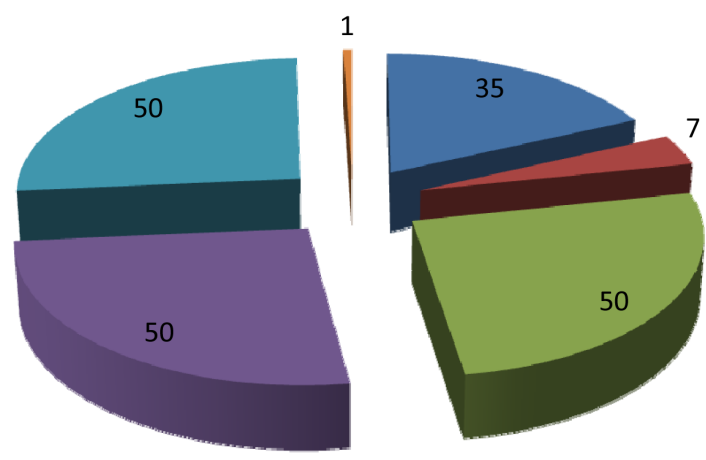

- Hypotension (Systolic BP $<100 \mathrm{mmHg}$ )

abdominal pain

- Abdominal Tenderness

nultiple Pellet marks on abdomen

Death

Figure 2. Showing No. of patients with different clinical findings in our study.

Table 2. Showing CECT findings of patients with pellet injuries to abdomen in our study.

\begin{tabular}{ccc}
\hline CECT FINDING & No. of patients & Percentage \\
\hline Pellets in parietal wall & 50 & $100 \%$ \\
Intra-peritoneal pellets & 46 & $92 \%$ \\
Pellets within bowel lumen & 37 & $74 \%$ \\
Pellets in solid organs (Liver; Spleen; Kidney) & 20 & $40 \%$ \\
Fluid in Peritoneal Cavity (Hemoperitoneum) & 36 & $72 \%$ \\
Pneumoperitoneum & 5 & $10 \%$ \\
Retroperitoneal Hematoma & 2 & $4 \%$ \\
Grade II or higher Splenic laceration & Nil & - \\
Grade II or higher liver laceration & Nil & - \\
\hline
\end{tabular}

Percentage does not correlate $100 \%$ as multiple findings were present in majority of patients. 

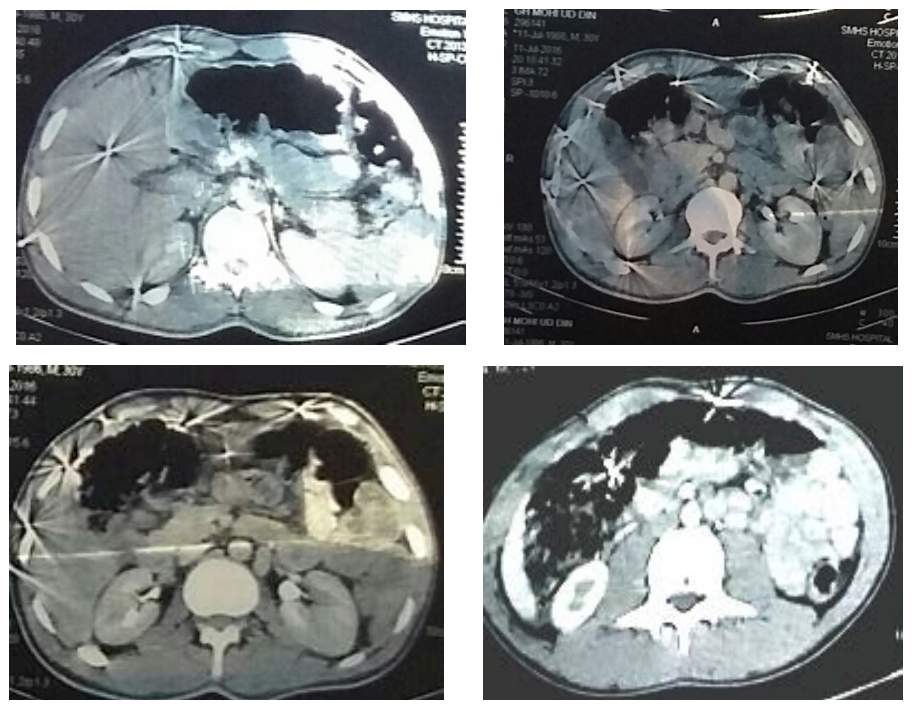

(a)
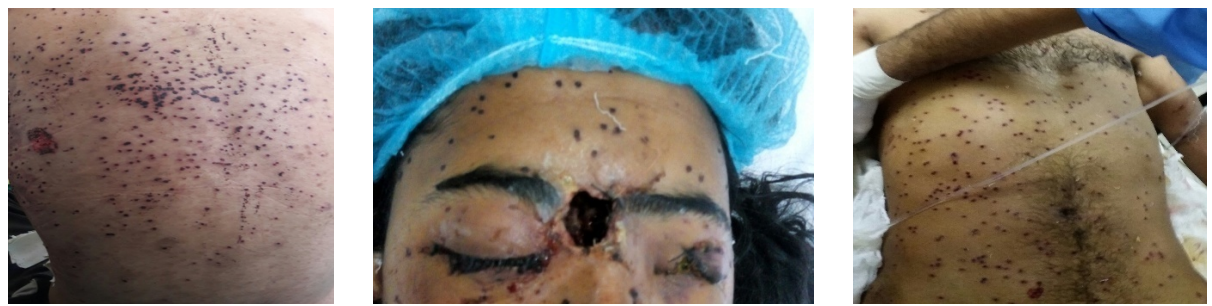

(b)
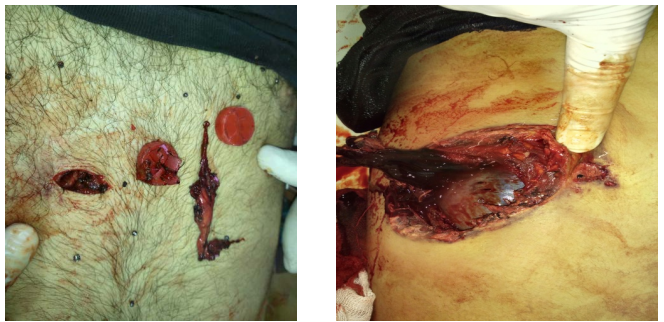

(c)
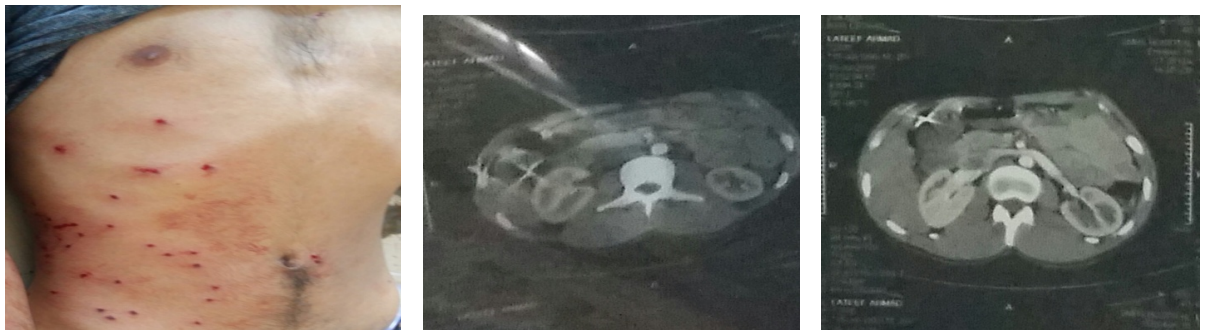

(d)

Figure 3. (a) CECT Images Showing Pellets in parietal wall and liver (Upper right); Pellets in parietal wall and Bowel lumen (Upper Left); Multiple Pellets in Parietal wall (Lower Right); Pellet in Transverse Colon (Lower Left); (b) Showing multiple pellets in a scatter pattern on the back of a young boy (Right) and face and eyes of a young girl (Middle), and whole abdomen (Left); (c) Showing close range pellet gun injury resulting in significant loss of parietal wall. The patient died; (d) Showing a patient with multiple pellets on parietal wall, with pellets in bowel lumen and peritoneal cavity. Patient did well with conservative management. 
The intra-operative findings and the operative procedures performed in our in our study are depicted in Table 3.

The predominant operative finding in our patients was multiple small puncture wounds on the bowel surface with serosal breaches but without mucosal eversion (83.33\%). The negative exploration rate in our study was $20 \%$. Overall closure of bowel perforations was the common procedure done in our study (32 patients), followed by resection of small bowel in 7 patient. 1 patient in our study had gastric perforation.

\section{Discussion}

Treatment of the injured patients has been a predominant mission of the surgeons since the origin of the medical care. Although the science of improving the management of injuries progresses continuously, it has been during the times of war that many of the greatest advancements were made because of the high burden of injuries during the relatively shorter periods and the different types of the injuries produced by the different varieties of the weaponry used $\mathrm{n}$ the wars. The surgeon involved in managing these injuries must be well aware with the peculiarities of these weapons and the nature of the injuries produced by them.

Since the beginning of armed struggle in Kashmir valley, the health care authorities have been receiving injuries which were no different from the conventional firearm injuries mentioned in the literature. But the introduction of "Pellet Guns" by the state police under the moniker of "Non Lethal weapon" as a more legitimate way of controlling mob and keeping peace posed a challenge to the health care authorities as the pattern, nature, severity and the assessment of these pellet injuries is not the same as is for conventional firearm injuries.

Table 3. Operative findings and operative procedures performed.

\begin{tabular}{|c|c|c|c|}
\hline OPERATIVE FINDINGS & $\begin{array}{l}\text { No. of } \\
\text { Patients }\end{array}$ & Percentage & $\begin{array}{l}\text { OPERATIVE PROCEDURE } \\
\text { PERFORMED }\end{array}$ \\
\hline Bowel perforation with everted mucosa & 7 & $23.33 \%$ & Closure of Small bowel perforations \\
\hline $\begin{array}{l}\text { Multiple Bowel perforation with serosal } \\
\text { breach only, no everted mucosa }\end{array}$ & 25 & $83.33 \%$ & $\begin{array}{l}\text { Closure of bowel } \\
\text { perforations/Resection } \\
\text { anastomosis of Small Bowel }\end{array}$ \\
\hline Mesenteric with hematoma & 3 & $10 \%$ & Peritoneal lavage \\
\hline Gastrocolic hematoma & 2 & $6.67 \%$ & $\begin{array}{l}\text { Ligation of bleeding } \\
\text { vessel in omentum }\end{array}$ \\
\hline Gastric perforation & 1 & $3.33 \%$ & Repair of Gastric perforation \\
\hline Splenic Hilar Injury & 1 & $3.33 \%$ & Splenectomy \\
\hline $\begin{array}{c}\text { Palpable pellets on liver Surface } \\
\text { with active bleeding }\end{array}$ & 3 & $10 \%$ & $\begin{array}{l}\text { Hemostasis of bleeding } \\
\text { pellet wounds }\end{array}$ \\
\hline $\begin{array}{l}\text { Mesenteric hematoma with unhealthy } \\
\text { bowel due to multiple serosal perforations } \\
\text { with marked erythema of the bowel wall }\end{array}$ & 4 & $13.33 \%$ & $\begin{array}{l}\text { Resection anastomosis } \\
\text { of Small Bowel }\end{array}$ \\
\hline No significant finding & 6 & $20 \%$ & Negative exploration \\
\hline
\end{tabular}


In 2010 episode of violence, a total of 198patients had suffered pellet injuries and the most common sites of injury were the extremities (47.9\%), abdomen (36.3\%) and chest (31.3\%) [3]. In our study, however, the commonest site of injury by pellets was Eyes and face $(65.13 \%)$ followed by Torso (19.07\%), head and neck (9.85\%) and extremities $(5.9 \%)$.

In our study, all patients (100\%) had multiple pellets Injuries in the abdominal wall Figure 3(b) and all the 50 patients (100\%) had abdominal pain and tenderness on examination and thus was very difficult to ascertain whether the pain and tenderness was because of pellet injuries in the parietal wall or because of intra abdominal injuries which were evident on CECT abdomen.

The predominant CECT finding in our study was the presence of multiple pellets in the parietal wall (100\% patients), intra-peritoneal pellets ( $92 \%$ patients) ,pellets inside hollow viscera(74\%) and free fluid in peritoneal cavity in (72\%) of patients. 6/30 patients $(20 \%)$ in our study had negative exploration. Majid mushtaque et al. [3] in their study also had negative laparotomy in 4 patients with pellet injuries to abdomen. Delayed laparotomy was done in3/20 patients in our study while as 17/20 patients did well with conservative management despite CECT showing multiple pellets in the parietal wall, presence of Pneumoperitoneum and pellets in bowel lumen Figure 3(d). This is comparable with Hegazy TO et al. [4] who in their study had 4/23 patients operated after 24 hours and all had hollow viscus perforations. So it can be argued that patients with pellets in parietal wall and even in bowel lumen can be well managed conservatively thus avoiding the morbidity associated with negative and unnecessary laparotomy [5] [6].

On the basis of intra-operative findings in patients who were explored, we observed that the predominant operative finding in our patients was multiple small puncture wounds on the bowel surface with serosal breaches but without mucosal eversion 25/30 (83.33\%), Bowel perforations with everted mucosa 7/30 (23.33\%), Mesenteric hematoma with unhealthy bowel due to multiple serosal perforations with marked erythema of the bowel wall 4/30 (13.33\%), Mesenteric hematoma alone 3/30 (10\%), gastrocolic hematoma $2 / 30$ (6.67\%), 1/30 patients had splenichilar injury (3.33\%), 3/30 patients (10\%) had Palpable pellets on liver Surface with active bleeding and 6/30 patients (20\%) had no significant finding on exploration. Bond et al. [7] and Majidmushtaque et al. [3] also reported that small bowel is the most frequently injured viscera in pellet injuries to abdomen and multiple bowel perforations being the common intra-operative finding.

In our study, on the basis of Clinical and CECT findings, 30/50 patients were operated, comparing these findings with their intra-operative findings it was observed that $18 / 33$ patients really needed exploration while as 15/33 patients could have been managed conservatively. Noting this high rate of un-necessary exploration, 20/50 patients with similar CECT findings were put on conservative management. Of these 20 patients, 17 did well while as 3 were explored later in view of developing peritonitis and all were found to have small bowel perforations.

On the basis of these findings, we observed that CECT abdomen though a gold Stan- 
dard investigation for assessing the abdominal injuries in penetrating firearm injuries is not an ideal investigation for assessing the abdominal visceral injuries produced by the pellets and for planning their management.

Chamisa [8] in his study on abdominal gunshot injuries observed that small bowel (59\%) was the most frequently injured organ, colon (37\%), liver (25\%) and stomach (22\%) and the injuries to small bowel being perforations and tangential lacerations, requiring resection (26\%) and simple closure (74\%). In our study we also observed small bowel as the most frequently injured organ and the type of injuries being perforations with everted mucosa $(23.33 \%)$ and perforations with serosal breach only, no everted mucosa $(83.33 \%)$ requiring either resection or simple closure. So it can be assumed that the intra-abdominal injuries caused by these pellets are no different from gunshot injuries though of lesser severity. Also, one patient with pellet injury in our study died who had received a close range pellet shot (Figure $3(\mathrm{c})$ ). Therefore, it can be said that although a "Non-Lethal Weapon" (NLW), it appears this description gives a false perception of the damage and injuries inflicted by the weapon.

\section{Conclusions}

Pellet Injury, a rare variant of trauma is a real dilemma for the health care authorities as the extent and severity of pellet induced abdominal visceral injury is not properly assessed by the Conventional available investigations for trauma like FAST and CECT abdomen, resulting in high rate of negative and unnecessary laparotomies. Therefore we suggest the use of "Diagnostic Laparoscopy" before proceeding to exploratory laparotomy in all patients with pellet induced abdominal visceral injuries who are found to require surgery on the basis of clinical and CECT findings thus reducing the need for unnecessary laparotomies, although, it may need further studies to validate the role of diagnostic laparoscopy in pellet induced abdominal trauma.

From this study, we also concluded that abdominal pellet trauma patients can be well managed conservatively until hemodynamically stable even though CT scan shows pellet penetration into peritoneal cavity or bowel lumen.

\section{References}

[1] Dar, A.M., Ahanger, A.G., Wani, R.A., Bhat, M.A., Lone, G.N., et al. (2003) Popliteal Artery Injuries: The Kashmir Experience. Journal of Trauma, 55, 362-365. http://dx.doi.org/10.1097/01.TA.0000052369.46364.4F

[2] Bell, M.J. (1971) The Management of Shotgun Wounds. Journal of Trauma, 11, 522-527. http://dx.doi.org/10.1097/00005373-197106000-00010

[3] Mushtaque, M., Mir, M.F., Bhat, M., Parray, F.Q., Khanday, S.A., Dar, R.A. and Malik, A.A. (2012) Pellet Gunfire Injuries among Agitated Mobs in Kashmir. Turkish Journal of Trauma \& Emergency Surgery, 18, 255-259. http://dx.doi.org/10.5505/tjtes.2012.47639

[4] Hegazy, T.O., et al. (2015) Assessment of the Management and Outcomes of Penetrating Abdominal Shotgun Injuries. International Surgery Journal, 2, 12-19.

[5] Renz, B. and Feliciano, D.V. (1995) Unnecessary Laparotomies for Trauma: A Prospective Study of Morbidity. Journal of Trauma, 38, 350-356. 
http://dx.doi.org/10.1097/00005373-199503000-00007

[6] Demetriades, D., Charalambides, D., Lakhoo, M. and Pantanowitz, D. (1991) Gunshot Wound of the Abdomen: Role of Selective Conservative Management. British Journal of Surgery, 78, 220-222. http://dx.doi.org/10.1002/bjs.1800780230

[7] Bond, S.J., Schnier, G.C. and Miller, F.B. (1996) Air-Powered Guns: Too Much Firepower to Be a Toy. Journal of Trauma, 41, 674-678.

http://dx.doi.org/10.1097/00005373-199610000-00013

[8] Chamisa, I. (2008) Civilian Abdominal Gunshot Wounds in Durban South Africa: A Prospective Study of 78 Cases. Annals of the Royal College of Surgeons of England, 90, 581586. http://dx.doi.org/10.1308/003588408X301118

Submit or recommend next manuscript to SCIRP and we will provide best service for you:

Accepting pre-submission inquiries through Email, Facebook, LinkedIn, Twitter, etc. A wide selection of journals (inclusive of 9 subjects, more than 200 journals)

Providing 24-hour high-quality service

User-friendly online submission system

Fair and swift peer-review system

Efficient typesetting and proofreading procedure

Display of the result of downloads and visits, as well as the number of cited articles Maximum dissemination of your research work

Submit your manuscript at: http://papersubmission.scirp.org/

Or contact ss@scirp.org 